\title{
EL "VACÍO" COMO CATALIZADOR DE LA ESCRITURA: "EL RETRATO DE ZOE" Y EL HIPOGEO SECRETO DE SALVADOR ELIZONDO
}

\author{
Petra Báder \\ Universidad Eötvös Loránd \\ bader.petra@btk.elte.hu
}

Resumen: El presente estudio indaga el concepto del "vacío", presentado por Ricardo Piglia en su "Secreto y narración. Tesis sobre la nouvelle", y su posible aplicación en dos obras del autor mexicano Salvador Elizondo: "El retrato de Zoe" y El hipogeo secreto. El ensayo de Piglia no representaría entonces un acercamiento a los textos elizondianos según el género de la nouvelle, sino ofrece unas consideraciones valiosas en cuanto al funcionamiento del concepto mencionado, hermanable con los de "abismo" y "búsqueda", proponiendo sus diferentes vertientes como catalizadores de la escritura.

Palabras clave: vacío, abismo, búsqueda, Salvador Elizondo, Ricardo Piglia

\section{THE "GAP" AS CATALYST FOR THE WRITING PROCESS: SALVADOR ELIZONDO'S “EL RETRATO DE ZOE” AND EL HISPOGEO SECRETO}

\begin{abstract}
This paper enquires into the notion of "gap", introduced by Ricardo Piglia in his "Secreto y narración. Tesis sobre la nouvelle" [Secret and Narration. Thesis on the Nouvelle], and its possible application to the Mexican Salvador Elizondo's works: "El retrato de Zoe" [Zoe's Portrait] and El hipogeo secreto (The Secret Crypt). In this paper, Piglia's essay would not come to mean an approach to Elizondo's works according to the genre of the nouvelle, but it offers some valuable considerations regarding the aforementioned notion's operation, connected to the concepts of the "abyss" and of the "search", because it proposes several aspects as being a catalyst for the writing process.
\end{abstract}

Keywords: gap, abyss, search, Salvador Elizondo, Ricardo Piglia

DOI: https://doi.org/10.24029/lejana.2020.13.431

Recibido: el 24 de noviembre de 2018

Aceptado: el 1 de marzo de 2019

Publicado: el 19 de febrero de 2020 


\section{El concepto del "vacío" en Elizondo y Piglia}

A menudo se habla de la narrativa de Salvador Elizondo, especialmente en lo que se refiere a sus dos novelas, como de una narrativa que se sustenta en la idea de la paradoja. Como indica el subtítulo de Farabeuf o la crónica de un instante, su primera novela, publicada en 1965, gira en torno a las (im)posibilidades de relatar acontecimientos simultáneos. Esta propuesta no le es exclusiva, ya que se repite en El hipogeo secreto, su segunda y última novela, publicada tres años después, en 1968; a pesar de las afinidades innegables que comparten las dos obras, al menos según indica el título de la segunda, parece que la paradoja temporal se desplaza hacia el ámbito espacial.

Existen acercamientos y lecturas múltiples de la narrativa de Elizondo; para la interpretación de sus obras, algunos toman como punto de partida sus ensayos, otros, la presencia de la intertextualidad y los discursos extraliterarios. Sin embargo, de entre estas aproximaciones múltiples, las que me interesan aquí interpretan la obra del autor mexicano, por una parte, basándose en el principio de la variación en que se sustenta la obra elizondiana - es el caso de Claudia L. Gutiérrez Piña en Las variaciones de la escritura. Una lectura crítica de El grafógrafo y de la obra de Salvador Elizondo - y, por otra parte, enfocándose en el carácter metatextual de sus escritos - como lo hace Norma Angélica Cuevas Velasco en El espacio poético en la narrativa. De los aportes de Maurice Blanchot a la teoría literaria y de algunas afinidades con la escritura de Salvador Elizondo - . Estos dos trabajos sobresalientes comparten varias afinidades de las cuales me gustaría destacar, incorporando otro ensayo reciente de Cuevas Velasco, "La brevedad en el taller literario de Salvador Elizondo", la coincidencia de conferir importancia capital a la variación, el fragmento y la brevedad, características que intervienen en los textos elizondianos sin excepción, incluso en sus dos novelas que, por su género, podrían escapar de la regla.

Con esto podríamos llegar a la reflexión sobre las diferencias entre el género del cuento y el de la novela, no obstante, Cuevas Velasco sostiene que "[1]a realidad palmaria es que los escritos de Elizondo rehúyen del encasillamiento genérico, la suya es una escritura sin la menor intención de procurar una única o exclusiva forma genérica. La escritura, como las ideas que aportan a la historia del pensamiento, debe existir sin amarras" (2016: 4). ${ }^{1}$ Una clave de justificación puede ser un ensayo del propio Elizondo, "Teoría mínima del libro", publicado en sus Cuadernos de escritura en 1969, en el que habla sobre la escritura a manera de realización de un proyecto (Elizondo, 2000d: 10) que se traza desde sus primeras páginas escritas (Cuevas Velasco, 2016: 6); este proyecto sería tomar los esbozos y darles vida en el libro (2000d: 11). Para Elizondo, los esbozos no son necesariamente escritos, son, más bien, realidades mentales, pertenecientes al pensamiento, por tanto su proyecto consiste en dar forma, objetivar, fijar, concretar y materializar, por el texto y la escritura, lo subjetivo, lo abstracto, lo móvil y lo mental, todo lo que pertenezca al ámbito del pensamiento (Gutiérrez Piña, 2016: 9). Si el texto es la materialización del pensamiento, la escritura es el medio de poder realizarlo.

\footnotetext{
${ }^{1}$ En las referencias a su artículo publicado en el número 9 de Lejana. Revista Crítica de Narrativa Breve, sin numeración continua en aquel entonces, sigo los números que aparecen en el PDF (recurso en línea).
} 
En el mismo "Teoría mínima de libro", Elizondo habla sobre dos tipos de textos: por una parte, existe "la novela" en la que el lector debe llenar los "vacíos" dejados por el escritor, y, por la otra, existen textos "sin vacíos" a los que el lector no puede agregar nada, ya que "la escritura misma agota las posibilidades de la lectura" (2000d: 13); huelga decir que los textos elizondianos pertenecen a la primera categoría. Esta tipología no solo tematiza los preceptos mínimos de los participantes (el emisor y el receptor) de cada obra literaria, sino que propone un concepto que me parece de clave para la interpretación de los textos elizondianos: el del "vacío". En "Teoría mínima del libro" sintetiza su reflexión y así, lo hasta ahora mencionado, de la siguiente forma:

[1]a finalidad de la escritura parece enturbiar su predominante condición de instrumento, de instrumento al servicio de la realización del proyecto; de una investigación acerca de la naturaleza de esa resistencia que la palabra opone a la infatigable corrosión del uso. Por ello todos los libros han sido escritos para ser leídos únicamente por sus autores. Media un interminable abismo entre la página y la mirada del lector; un abismo tan vasto como el que se abre entre el escritor y la cuartilla; las más de las veces la estructura, el andamiaje que sustenta al discurso, se queda en el tintero. (2000d: 10, las cursivas son mías)

Aunque la idea de que el lector debe colmar los vacíos ("abismos") de significado que el autor ha dejado abiertos durante el proceso de lectura es un planteamiento bien conocido de los estudios hermenéuticos, Elizondo le añade un nuevo uso para poder subrayar la dificultad de la escritura, ya que esta no solo radica en el carácter "usado" y, por tanto, insuficiente del lenguaje, sino también en los obstáculos con los que se enfrenta el autor a la hora de representar la idea (lo inmaterial) por la escritura (como medio) en el texto (lo material). De la misma preocupación elizondiana llama la atención Enkratisz Révész en su tesis doctoral "El asedio del enigma y la subversión en la temprana cuentística de Salvador Elizondo". La investigadora reflexiona sobre los primeros cuentos del autor mexicano interpretándolos como "formulaciones del enigma" (2003: 178) en las que se trata del afán de descifrar (buscar) el enigma del otro y del deseo paralelo de proyectar el otro en la mente del yo, sin que haya un nosotros (2003: 180). Este acercamiento pone de relieve que este enigma podría ser otra vertiente del "vacío" que media entre el escritor y la cuartilla en frente.

En un contexto completamente diferente, en su reflexión sobre la forma de la novela corta y por tanto los posibles criterios de diferenciación entre géneros narrativos, Ricardo Piglia reflexiona sobre lo que él denomina "vacíos" de la siguiente forma:

[e]ntonces, el enigma sería, como sabemos, incluso por etimología, la existencia de algún elemento - puede ser un texto, una situación...- que encierra un sentido que es necesario descifrar. [...]

El misterio, en cambio, sería un elemento que no se comprende porque no tiene explicación, o que al menos no la tiene en la lógica dentro de la cual nosotros nos manejamos. $[\ldots]$

En cuanto al secreto, se trata también de un vacio de significación, es algo que se quiere saber y no se sabe, como el enigma y el misterio, pero en este caso es algo que alguien tiene y no dice. Es decir, el secreto es en verdad un sentido sustraido por alguien. Entonces, el texto gira en el vacio de eso que no está dicho [...]. (2006: 187-190, las cursivas son mías)

\footnotetext{
${ }^{2}$ Me parece que, en este caso, la indicación del género de la novela no es premeditada, sino que se usa como sinónimo de texto (literario).
} 
Si el cuento, para Piglia, "es un relato que encierra un relato secreto" (2006: 187), es decir, en el que se cuentan dos historias (necesariamente: una explícita y otra implícita), según su función narrativa, el secreto

sería un lugar vacío que permite unir tramas narrativas diversas y personajes distintos que conviven en un espacio atados por ese nudo que no se explica. [...] Es decir, que el secreto funciona como un mecanismo de construcción de la trama porque permite unir sobre un punto ciego una red de pequeñas historias que se articulan, de una manera inexplicable, pero se articulan. De ahí la sensación de ambigüedad, de indecisión, de las múltiples significaciones que tiene una historia [...]. (2006: 200, las cursivas son mías)

En cambio, la nouvelle "recurre al secreto para poder concentrar historias múltiples, es un cuento contado muchas veces. La nouvelle, entonces, como hipercuento, especie de versión condensada de cuentos múltiples que se van anudando en una historia que, sin embargo, no se disgrega porque se anuda en un punto oscuro" (2006: 201).

En estas extensas citas, Piglia no solo esboza una tipología de los "vacíos" con su definición correspondiente, sino que de entre las líneas suyas también se insinúan las tesis de la novela corta. Frente a las dos tesis del cuento ("Primera tesis: un cuento siempre cuenta dos historias" y "Segunda tesis: la historia secreta es la clave de la forma del cuento" [2000: 17$18]),{ }^{3}$ en "Secreto y narración. Tesis sobre la nouvelle" se perfilan seis tesis de la novela corta, sin ser numeradas, las que intento reconstruir en lo que sigue, siempre comparando con sus afirmaciones sobre el cuento:

Primera tesis: A diferencia del cuento, la nouvelle nunca descifra por completo los enigmas que plantea (2006: 194).

Segunda tesis: El secreto, como función narrativa, es el mecanismo de construcción tanto del cuento como de la nouvelle (200).

Tercera tesis: La nouvelle es un hipercuento, es decir, un cuento muchas veces contado (201).

Cuarta tesis: Tanto el cuento como la nouvelle mantienen el marco del relato oral (201).

Quinta tesis: El lector del cuento y de la nouvelle es que tiene que narrar (202).

Sexta tesis: A diferencia del cuento, el final de la nouvelle no coincide con el final mismo de la historia (204).

Si estas seis tesis son correctamente detectadas, en la primera y la última se acentúan dos diferencias principales entre cuento y novela corta y, lo que más me interesa aquí, estas dos divergencias son recíprocas, porque se refieren al final tanto escrito como interpretativo de las obras pertenecientes a los dos géneros en cuestión. Cabe añadir que estas mismas tesis aclaran la diferencia entre secreto y enigma, trazada ya al principio del mismo ensayo pigliano: en caso del cuento, hablamos sobre secreto porque al final este se revela, es decir, el final de las dos historias narradas (la explícita y la implícita) necesariamente coincide; sin embargo, en la nouvelle no hablamos de secreto, sino de enigma, puesto que, como el final de las múltiples

\footnotetext{
${ }^{3}$ En sus "Nuevas tesis sobre el cuento", Piglia añade a sus consideraciones la importancia de la tensión y la de cerrar las historias siempre con ambigüedad, el hecho de que el cuento mantiene sus vínculos con la oralidad, la importancia del lector en el proceso de desciframiento (a través de los ejemplos de los cuentos de Borges) y, por último, la estructura del secreto.
} 
historias narradas no coincide al final del texto, el significado del enigma no queda descifrado.

Después de este largo excurso sobre los términos usados por Ricardo Piglia, ¿por qué usar sus consideraciones si se ha dicho al principio que los textos de Salvador Elizondo escapan de cualquier categoría genérica? El propósito del presente ensayo de ninguna manera es clasificar las obras elizondianas según su pertenencia a un género u otro, sino más bien reflexionar sobre el concepto del "vacío", principalmente el enigma, que Piglia propone como un elemento a descifrar. Como se verá, en las obras de Salvador Elizondo, este intento de desciframiento no solo se realiza de parte del lector - de lo que se han hablado varios investigadores de Farabeuf o la crónica de un instante-, sino también de parte del narrador $\mathrm{y}$, en última instancia, del mismo autor, ya que "la brevedad de la escritura [es] la única forma posible mediante la cual la memoria o el pensamiento logran romper la barrera invisible que los separa de la hoja en blanco" (Cuevas Velasco, 2016: 10).

En cuanto al corpus del que se pretende reflexionar en las siguientes páginas cabe subrayar que, basándose en la diferenciación de los géneros propuesta por Ricardo Piglia, lo lógico sería elegir la única novela corta propiamente dicha de Salvador Elizondo, Elsinore: un cuaderno (1988). Sin embargo, como Cuevas Velasco afirma sobre dicha novela que, para Elizondo, "los géneros no son formas que existan de antemano, es la escritura, el lenguaje quien los revela. [...] el aporte estético de Elsinore no radica en ser una novela corta" (Cuevas Velasco, 2012: 2), he considerado más importante elegir el corpus por analizar, según los siguientes criterios: me ha parecido importante elegir dos textos de extensión distinta para poder ofrecer una lectura contrastiva del funcionamiento del "vacío" como catalizador de la escritura elizondiana. Como este motivo paralelo al de la búsqueda se percibe en la mayoría de las obras del autor mexicano, mi segundo criterio ha sido buscar dos obras entre las que haya una evolución directa. He elegido, por tanto, "El retrato de Zoe", publicado por primera vez en el número octavo de la Revista de la Universidad de México, en 1968, y después integrado en El retrato de Zoe y otras mentiras, publicado un año después, en 1969. Según Gutiérrez Piña, los textos que integran la antología elizondiana son una especie de "laboratorio donde el autor ensaya formas y recursos de manera paralela en los géneros novela y relato corto", que se interpreta como un vuelco hacia la hibridez de discursos (2016: 108). De entre las novelas de Elizondo me parece más conveniente destacar El hipogeo secreto, publicado en 1968, por la simple razón de que sus años de gestación coinciden con la de "El retrato de Zoe".

\section{Los "vacíos" en "El retrato de Zoe" y El hipogeo secreto}

El lector de "El retrato de Zoe" encara una tarea sumamente difícil, ya que su interpretación se ve desorientada desde la primera frase: "[n]o sé siquiera si ése es su verdadero nombre" (Elizondo, 2000c: 11). ${ }^{4}$ El título de este texto, relacionado con la pintura, y su arranque negado evocan de alguna forma, aunque sus fines estéticos diverjan, La obra maestra desconocida (1831) de Honoré de Balzac, donde aparece un cuadro que se ve, pero no se

\footnotetext{
${ }^{4}$ Como todas las referencias comprenden la misma edición del texto, de aquí en adelante solo se señalan los números de página correspondientes.
} 
entiende. El motivo de la ininteligibilidad es patente en el relato elizondiano también: "[a Zoe] [1] a fui aprendiendo poco a poco" (11), dice el narrador al principio, luego se refiere a su "carácter ilusorio y abstracto" (13), después afirma que "[s]u inexplicabilidad era el atributo que todos aprendimos amar en ella" (17, la cursiva es mía) y, por último, habla sobre la imposibilidad de evocar a Zoe (21, la cursiva es mía). Pero en este relato, a diferencia de lo que pasa en la obra de Balzac donde se tiene una obra concreta y material, el retrato de Zoe pertenece al ámbito de lo inmaterial, siendo una especie de castillo en el aire: "lo único que aprendí acerca de ella fue su ausencia" (11, la cursiva es mía).

Tenemos el marco del retrato, pero la imagen es borrosa y, por tanto, necesaria de reconstruir. A pesar de que la figura de Zoe es una ausencia visual - o justo por esta misma razón-, tiene la capacidad de convertirse en una marcada presencia textual: el nombre de la muchacha aparece 22 veces a lo largo del cuento. ${ }^{5}$ Pero la reconstrucción del retrato no solo es la tarea del lector, sino también la del narrador: "sólo sé de ella lo que ya no sigue siendo" (12, la cursiva es mía). El texto es un monólogo interior - una especie de flujo de conciencia a lo Joyce - determinado por la ausencia/presencia de Zoe, cuya identidad se intenta revelar investigando el ámbito del recuerdo ${ }^{6}$ y de la realidad: "[e]ra la ausencia de Zoe la que determinaba [...] el carácter inquietante de todo lo que hicimos y de todo lo que se hubiera podido hacer allí" (15). Aunque el narrador habla al principio sobre su capacidad de poder reconstruir la imagen de Zoe de lo que es su ausencia, unas páginas más adelante expresa la necesidad de "llenar la ausencia" (16), hasta llegar a la conclusión de que Zoe era una "enorme mentira" (18), una "mentira significativa" (20).

A pesar de que se afirma que, en realidad, "da igual cómo se llama" (15), ${ }^{7}$ el significado del nombre de Zoe sí es relevante: "vida". De hecho, parece que Elizondo traza un signo de igualdad entre mentira (mencionada 8 veces en el texto) y vida (hasta 12 veces): "[1]a vida nos había enseñado a contar mentiras; a contar tantas mentiras que todo nuestro universo ficticio nos parecía más real que la mentira real que ella era" (17, las cursivas son mías). En la cita se revela la influencia de Jorge Luis Borges y de su idea del carácter más real del mundo ficcional que el de la propia realidad. ${ }^{8}$ Pero lo que contrasta de manera más patente con la imagen ausente y, por tanto, intangible de Zoe es el carácter material y, por tanto, tangible del tú. El uso de la segunda persona del singular y del vocativo que la corresponde no es una novedad en la narrativa de Elizondo, ya aparece en su primera novela, Farabeuf o la crónica de un instante, publicada tres años antes de la aparición de "El retrato de Zoe", y también aparecerá en su segunda novela, El hipogeo secreto. Si se ha dicho que la figura de Zoe es una marcada presencia textual por aparecer hasta 22 veces en el texto, compárese con el tú que aparece 34 veces. También se enfatiza el carácter real del tú que aparece como realidad corporal: "[t]ú en cambio eres real" (19) y "yo estoy aquí, a tu lado, junto a tu cuerpo" (21).

\footnotetext{
${ }^{5}$ Podría mencionarse su afinidad con el carácter del personaje prometido de Samuel Beckett en su Esperando a Godot (1953).

${ }^{6}$ De hecho, la palabra "recuerdo" aparece 12 , mientras que "memoria" 6 veces en el texto.

${ }^{7}$ Con esto también se refiere a la posibilidad de diversas identidades expresando en una cita precedente: “[...] tendían a acentuar el carácter totalmente sospechoso de esa identidad con la que la mía llegó a confundirse algunas veces" (12).

${ }^{8}$ Para conocer más puntos en común entre Borges y Elizondo, véase Eduardo Becerra: "Borges y Elizondo: la literatura hacia el desenmascaramiento de la realidad".
} 
El "vacío" que es la figura de Zoe, que "iba creando huecos que son el recuerdo de sus gestos y de sus actitudes que se dibujan" (18, la cursiva es mía) asimismo forma otro "vacío": el que media entre Zoe y el tú, entre esa "mentira real" inmaterial y la otra — se podría decir - realidad real material-corporal. Como se ha mencionado, Enkratisz Révész interpreta los primeros textos elizondianos según la formulación del enigma, de ese "vacío" del otro que se intenta descifrar, lectura también válida para "El retrato de Zoe", cuyo último párrafo, al menos a mi parecer, es una bella declaración de amor que contrasta manifiestamente con la representación casi sádica del cuerpo femenino en las dos novelas de Elizondo: "[y]o quiero conocerte ahora como se conoce una montaña y no como se ignora una caverna. Ven, ven, aquí junto a mí. Te lo imploro. Ven. Que nunca haya olvido entre tú y yo" (22). Si la montaña es el cuerpo del tú que se anhela conocer, la caverna es la imagen ignorada, ausente de Zoe; sin embargo, y en realidad, la caverna precisa la presencia de la montaña: el antónimo es aparente, generado por el enfrentamiento entre conocimiento e ignorancia.

La imagen y, sobre todo, la forma de la caverna, principalmente por su carácter sombrío, se hermana con la del hipogeo que forma parte del título de la segunda novela de Salvador Elizondo. Es más, en la primera página de El hipogeo secreto se repite el opuesto arriba citado, establecido por el enfrentamiento entre olvido y recuerdo, el último como sinónimo de conocimiento: "[r]ecuerda y olvida esa llaga luminosa; tres veces seguidas. [...] recuerda y olvida tres veces seguidas las palabras escritas en este libro; recuerda y desgasta las palabras contenidas en esta página..." (2000b: 9). ${ }^{9}$ La lectura de las primera páginas revela las características principales de la obra: por una parte, se trata de una novela que se autorrefiere de manera constante y que, por tanto, tematiza el proceso de su propia escritura por el que el autor se convierte en personaje; por otra parte, los fragmentos recién citados evidencian que la repetición — según lo demuestra Claudia L. Gutiérrez Piña- es uno de los recursos par excellence elizondianos.

La variación no solo se descubre dentro de la novela por la presencia de varios hilos narrativos — si se quiere, a la pigliana, de varias historias contadas, de historias múltiples-, sino también se dirige "hacia fuera" debido a la repetición de motivos (el más patente: el del espejo), de recursos narrativos y temas que se reiteran en los textos elizondianos. De entre ellos cabe subrayar algunas afinidades con Farabeuf o la crónica de un instante y el arriba analizado "El retrato de Zoe": en El hipogeo secreto se repite, por ejemplo, el oxímoron del subtítulo y el motivo de la fotografía del supliciado y los verdugos de la primera novela de Elizondo, en la imagen del ámbar, "congelación de un vuelo de una efímera; es decir, la suspensión de un movimiento comenzado a ser realizado hace cincuenta mil años" (17). Asimismo se reitera el uso de la segunda persona del singular y del vocativo correspondiente (también presente en "El retrato de Zoe") y la representación de la mujer en el contexto de un rito religioso-sexual-sádico. Se podría alargar la lista, sin embargo, me parece más oportuno buscar una interpretación del porqué de la recurrencia de dichos motivos y discursos que, no se ha de olvidar, necesariamente forman parte de la realización del proyecto elizondiano; según la interpretación de Norma Angélica Cuevas Velasco, la búsqueda no es temática sino

\footnotetext{
${ }^{9}$ Como todas las referencias comprenden la misma edición del texto, de aquí en adelante solo se señalan los números de página correspondientes.
} 
discursiva, pues "sólo a través de la palabra enunciada [...] se abre la posibilidad de emprender la búsqueda del ser de la escritura" (2016: 9).

A pesar de que no hay muchos acontecimientos en El hipogeo secreto, es difícil resumir el argumento de la novela; se podría decir que trata de una sociedad secreta, el Urkreis, cuyos miembros procuran buscar a su propio creador, el Imaginado, con el propósito de asesinarlo, cuya identidad se confunde a menudo con la del personaje Salvador Elizondo, desdoblado a la vez en el pseudo-Salvador Elizondo. El texto que estamos leyendo corresponde a un texto que se está siendo escrito: “[u]n escalofrío conmueve la mano con que escribo la crónica; las letras con las que el rito se instaura se congelan" (14) o "este libro, es un presente eterno hacia el que se fugan todas las perspectivas del tiempo, que necesariamente son más de tres" (21), o bien "estoy escribiendo una novela de la que ignoro todo. Sólo supongo el esquema general de la trama. Se trata de un escritor que escribe un libro" (44). Estos pasajes tendrán su eco en la imagen del grafógrafo de su antología homónima publicada en 1972, pero también forman parte de una serie de intentos, de parte de los narradores múltiples, por definir lo que sería la novela; para citar algunos ejemplos se podría mencionar que El hipogeo secreto contiene varias alusiones a los cuadernos de notas del propio Elizondo, en el que se encuentran "caóticamente dispersas innumerables observaciones, ideas, posibilidades relativas a la composición de El Hipogeo Secreto" (76, nótese el uso de las mayúsculas en las iniciales). Otro ejemplo son los intentos de definición de la propia novela, que se concibe como un juego (96), una serie de "posibles novelas" (96, recuérdese lo dicho por Piglia), o bien "la representación de un universo absolutamente gerundial; una trama que en todo momento está siendo iniciada y en ninguno tiene un desenlace... todavía" (98-99). La última cita tematiza no solo el presente sino también el porvenir de la escritura; en El hipogeo secreto, esto también se logra por el uso de la estructura circular y el recurso de los tres puntos suspensivos: “...Dime, te imploro —dice_- [...]” (9) y “—_Ahora!..." (164); por tanto la novela termina enfatizando "un presente que tiende a eternizarse en las páginas de este libro" (68).

La escritura se concibe, de manera explícita, como una "realidad paralela" (35), pero también "existe un número infinito de ríos heráclitos de la realidad" (122). Con esto se tematiza la alusión a las versiones, a la variación, que tanto en esta como en otras obras del autor se suelen denominar "conjeturas" (34). Este vocablo guarda un estrecho vínculo con los conceptos hasta aquí usados, por una parte, con el principio de la variación en tanto sinónimo de versiones de suposiciones y, por la otra, con "vacío" y "búsqueda", ya que en el fondo de cada conjetura se esconde un "vacío" de significación: algo que no se sabe, pero que de alguna forma se intenta explicar o justificar. En la novela se descubre una reflexión sobre el mismo motivo: "[t]oda escritura es el intento de comprender y de transmitir una visión que es quizá o tal vez incomprensible, quizá o tal vez incomunicable. [...] toda escritura es la concreción de un insomnio y la creación literaria a una aspiración irrefrenable de sueño" (54). El principio de la variación, en caso de esta novela, corresponde al ars combinatoria (36), que se refiere a las diferentes versiones de la historia en proceso de escritura - si se quiere seguir lo dicho en el ensayo pigliano, se trata de múltiples historias en una-, pero asimismo concierne a los personajes de la obra. A este respecto cabe reflexionar sobre el porqué de la falta de nombres propios, salvo el del autor, que se suplantan, de un lado, por nombres genéricos como Mía, la Perra, el Imaginado, el Mago o el Sabelotodo, referentes en la 
mayoría de los casos al ámbito del rito religioso, y, de otro lado, por algunos iniciales en mayúscula. Estos últimos expresan una riqueza semántica, ya que pueden contar con identidades reemplazables, que - junto con el recurso del flujo de conciencia - tal vez evidencie la huella de Finnegans Wake de James Joyce, del que también procede el epígrafe de la novela a cuya traducción también aspiraba el propio Elizondo. ${ }^{10}$

La novela termina con el asesinato del Imaginado, ideador del mundo en que se encuentran los personajes de El hipogeo secreto, concebido como una ciudad, la de Polt, que es, al mismo tiempo, "espacialización del sueño [del Imaginado]" (27), cuya arquitectura es "el reflejo del caos en un espejo que todo lo ordena" (27). Los personajes lo encuentran tras un largo proceso de búsqueda; primero avanzan por un "pasadizo sombrío" (137), una especie de túnel que, al paso del tiempo, se convierte en una forma geométrica, una construcción laberíntica pero infinita, ${ }^{11}$ que los lleva hacia un "centro en el que el tiempo no transcurre ya: imagen estática del mundo, un trasfondo de sus propios sueños" (137, la cursiva es mía y sería, aquí, sinónimo de hipogeo). El carácter especular de la ciudad tiene su eco en una imagen sumamente interesante que implica una inversión: el Imaginado está soñando a la realidad donde viven los personajes en su busca, sin embargo, como indica su nombre, es alguien que se está soñado, imaginado; una vez llegados los personajes muy cerca del Imaginado, y así, del hipogeo secreto, se escucha un disparo; en ese instante, las interminables frases de las páginas anteriores dan su lugar a frases sumamente cortas y entrecortadas, en las que el presente simple y continuo y el futuro van dejando cada vez más lugar a los imperativos (véase, por ejemplo, los cambios producidos entre las páginas 154 y 164); de manera paralela, hay cada vez más alusiones al carácter especular de las imágenes que ven los personajes: "[l]o que pasa es que estás del otro lado del espejo y allí las páginas del libro se suceden en sentido inverso, ¿entiendes? [...] Pasa más páginas, pero al revés...” (161).

El espejo es uno de los motivos más recurrentes de la narrativa elizondiana, asimismo aparece en su trabajo ensayístico de cavilaciones sobre la escritura. Tiene que ver en general con una red de oposiciones, ya que se concibe como límite o umbral entre dos realidades paralelas, que pueden ser la escritura y la lectura, como sugieren los fragmentos recién citados; al mismo tiempo, el reflejo del yo en el espejo tematiza su enajenación de sí mismo para ser otro y poder contemplarse desde fuera. En ambos casos es relevante el motivo de la mirada, pero no se concibe como obstáculo para la realización del proyecto. En Farabeuf o la crónica de un instante, por ejemplo, el espejo sirve como medio que facilita la comunicación de los personajes que se encuentran en diferentes planos espacio-temporales, o hace posible la unión de dos personales generalizados, él y ella (véase, por ejemplo, 2000a: 168). En El hipogeo secreto, el espejo se refiere tanto a la estructura novelesca en cuanto tematiza la escritura y también la lectura "gerundiales" y simultáneas como a la contemplación como actividad primordial de los personajes, por ejemplo, en "me miro mirando un espectáculo" (20).

En las últimas páginas de la novela, a medida que los personajes vayan avanzando en el túnel que les lleva hacia el centro, hacia el hipogeo secreto, las pistas y explicaciones que se

10 El texto asimismo aparece en una edición de 1992 de ensayos elizondianos reunidos: Teoría del infierno. México: Fondo de Cultura Económica (Letras Mexicanas), 2013 [1992]: 145-150.

${ }^{11}$ Claudia L. Gutiérrez Piña analiza de manera detallada dos formas geométricas al respecto: la Banda de Möebius y la Botella de Klein, véase 2016: 104-105. 
ofrecen al lector casi sin excepción se refieren al carácter especular del recinto. A la hora de llegar al hipogeo, que es paradójicamente el mismo lugar de donde partieron — porque es la conciencia misma de su creador-, dicen los personajes que serán "otros. Seremos ya los que el Imaginado está escribiendo. Palabras definidas, unívocas" (139). Se trata de un proceso de inversión que aparece especializado unas páginas atrás, cuando los personajes entran en el paisaje visto desde la ventana de E., un personaje que los acompaña en un tramo, como si salieran al mismo tiempo de su cabeza o miraran desde sus ojos (ventanas). De hecho, al descubrir al Imaginado, ven que "[e]stá escribiendo al revés" (163). El acto de la penetración en el hipogeo secreto, este paso hacia "el revés", se concibe como "un tránsito misterioso hacia un fondo más bajo de las palabras. Hacia el fondo en el que todavía no están disociadas de la substancia que las hace significativas como representaciones escritas de una realidad que les es totalmente ajena" (162, las cursivas son mías), por tanto concibe la realidad, a manera de Borges, como realidad únicamente textual o escritural que no puede escapar del pensamiento y del lenguaje.

El carácter especular de las imágenes visuales y de la trama alude al fin y al cabo al carácter especular del texto. Por esta razón, Norma Angélica Cuevas Velasco concibe El hipogeo secreto como desnovela ${ }^{12}$ o desobra, des-escritura en que el proceso de la escritura parece paralelo no solo al de la lectura, sino también con el de ir fundamentando la poética propia de la misma (2006: 212-213): "[1]a escritura de la desnovela implica la búsqueda de un centro que pertenece a la obra, pero que se diluye en la indagación de la misma; la obra carece de centro y su punto central es la obra misma" (2006: 217, las cursivas son mías). El proyecto literario de Salvador Elizondo, centrado en el concepto de la búsqueda, llega a su madurez en la segunda mitad de los sesenta, para dar lugar a su obra cumbre, El grafógrafo (1972), cuyos cuentos recurren, según ha demostrado Claudia L. Gutiérrez Piña, al principio de la variación; en El hipogeo secreto se detecta una suerte de movimiento entre dar forma al texto y transformar sus propios contenidos (Gutiérrez Piña, 2016: 98). Si dar forma corresponde al carácter "gerundial" del texto que se está siendo escrito, la transformación de sus contenidos tematiza la necesidad de la (re)lectura, una especie de antecedente del cuento "Mnemothreptos" de El grafógrafo, en que la relectura de lo anteriormente escrito cataliza la creación de las variaciones (¿infinitas?) de la escritura. De su parte, Luz Elena Gutiérrez de Velasco Romo, quien ofrece el primer análisis detallado de Farabeuf o la crónica de un instante, detecta otro motivo que le recuerda al del movimiento: "[1]os fragmentos de Farabuef, que antes hemos considerado como trozos de un texto-cadáver, adquieren movimiento cuando son vistos en la perspectiva del texto anárquico, que se encuentra en constante huida para no topar con el sentido. Sin embargo, el sentido recobra sus fueros en la huida misma" (1984: 24); ese "no topar con el sentido" es otra vertiente del "abismo", es algo que se nos escapa, pero que comprende el mismo gesto de búsqueda.

\footnotetext{
12 "Una desnovela sería un tipo de relato que sin permitirnos hacer a un lado su narratividad, es decir, sin dejar de ser novela, nos involucra en el modo en cómo se interrumpe tal acentuación para dar cabida a un metatexto que describe, no los acontecimientos a la representación de los mismos, sino el fenómeno de la escritura" (2006: 217). Por tanto, Cuevas Velasco no concibe El hipogeo secreto como una novela experimental, sino como una serie de metatextos narrados (2006: 214).
} 


\section{Conclusiones}

Tanto la imagen olvidada de Zoe como el hipogeo mental-espacial de la novela elizondiana corresponderían a un "vacío", al que la única forma de llegar es a través de un proceso de búsqueda. Son imágenes mentales borrosas e inciertas, a manera de puntos de fuga donde convergen las ideas que corresponden a ese "vacío", son — con palabras de Cuevas Velascohilos (a manera de historias múltiples) que fundamentan el laberinto de El hipogeo secreto, "la verdad textual que es la novela" (2006: 216). Se busca "el ser real" (Elizondo, 2000b: 58), personificado en la imagen del Imaginado, creador del texto que se está escribiendo, pero que, como sugiere su nombre, se está siendo contemplado, como el texto mismo, dentro de un espejo. Detrás de las palabras que forman las obras elizondianas aquí estudiadas, ese "ser real" es un "vacío" de significación, un referente al que se alude constantemente, pero que es imposible revelar, ya que su descubrimiento, como el del hipogeo secreto, desencadenaría una serie de imágenes especulares que no se refieren a otro que es la misma novela, el acto de la misma escritura: "[t]odas las formas y los personajes representados son el fondo sobre el que otra realidad está proyectada. [...] el dibujo representa el reflejo de un yo que se mira a sí mismo reflejado en un espejo" (Elizondo, 2000b: 69, las cursivas son mías). Esta "otra realidad" es el "fondo secreto del enigma" (Elizondo, 2000b: 114), el "vacío" que es catalizador y, al mismo tiempo, objetivo de la escritura, y que comprende a la vez la multiplicación de posibilidades, hilos narrativos, identidades y perspectivas: conjeturas de una "búsqueda [...] milenaria" (Elizondo, 2000b: 156), que se dirige al centro, a la fuente, al lenguaje, al "último secreto de la existencia" (Révész, 2003: 21).

En "Teoría mínima del libro" se ha trazado el esbozo de una novela cuyo lector debe colmar los "vacíos" dejados por el escritor, un sentido sustraído, como el secreto definido por Ricardo Piglia: un elemento que alguien conoce (en este caso, el autor), pero no se lo dice al otro (en última instancia, al lector). Sin embargo, el "abismo" que se abre entre el autor y la cuartilla alude a otro tipo de "vacío" y la consiguiente búsqueda de un elemento que "encierra un sentido que es necesario descifrar" (Piglia, 2006: 188). ${ }^{13}$ El precepto del "relato secreto" o implícito, exigido por Piglia en su tesis primera del género cuentístico ("un cuento siempre cuenta dos historias"), junto con la ambigüedad respectiva, se detecta de manera evidente en "El retrato de Zoe". Si El hipogeo secreto fuera una nouvelle, en ella debería recurrirse al secreto - que luego Piglia reemplaza por el concepto del enigma, con lo que genera reparos innegables - para poder contar historias múltiples. Ese "punto oscuro" (Piglia, 2006: 201) en que se anudan los cuentos múltiples, en caso de Elizondo, son conjeturas y variaciones que corresponden a la vez al "vacío" de significación al que intentan llegar tanto los personajes como los lectores y, al fin y al cabo, el autor de El hipogeo secreto.

Esto sí es palpable en esta obra de Salvador Elizondo, llamada novela más por la convención genérica, pero que también corresponde a las características de la nouvelle trazadas por Ricardo Piglia. Este hecho, que indudablemente requiere meditación postrera en otra ocasión, parece poner entre signos de interrogación la exclusividad de las consideraciones de Piglia en cuanto al género de la novela corta; pero también del cuento, ya que no toma en consideración, como el propio Elizondo en su “Teoría mínima del libro", que existen otro tipo

\footnotetext{
${ }^{13}$ Yo descartaría, al menos según la definición ofrecida por Piglia, la interpretación del "vacío" elizondiano como misterio, es decir, algo que no tiene explicación dentro de la lógica — esta vez — textual.
} 
de textos: los que - a mi parecer, independientemente de su género - no dejan abierto ningún "vacío" para ser colmado por sus lectores. Los ensayos piglianos aquí estudiados, a pesar de la innegable calidad de sus propuestas, hablan sobre un tipo de cuento y un tipo de novela ¿corta?, a mi parecer, según sus propios gustos.

\section{Bibliografía}

BALZAC, Honoré de (2000): La obra maestra desconocida. Intr. María Minera. Trad. Ernestina de Champourcin. Buenos Aires, Fondo de Cultura Económica de Argentina.

BECERRA, Eduardo (1994): "Borges y Elizondo: la literatura hacia el desenmascaramiento de la realidad". Cuadernos para la Investigación de la Literatura Hispánica 19 (1994): 255-264.

CUEVAS VELASCO, Norma Angélica (2006): El espacio poético en la narrativa. De los aportes de Maurice Blanchot a la teoría literaria y de algunas afinidades con la escritura de Salvador Elizondo. México, Universidad Autónoma Metropolitana.

--- (2012): "Atisbos del pensamiento literario de Salvador Elizondo". $2^{\circ}$ Coloquio Internacional de La Novela Corta en México 1922-2012. México, Universidad Nacional Autónoma de México, sinopsis disponible en: https://docplayer.es/59776235-2o-coloquio-internacional-la-novela-corta-enmexico.html [20/01/2020].

--- (2016): "La brevedad en el taller literario de Salvador Elizondo". Lejana. Revista Crítica de Narrativa Breve 9 (2016). Recuperado de: http://ojs.elte.hu/index.php/lejana/article/view/102/95 [21/09/2018]. DOI: https://doi.org/10.24029/lejana.2016.9.102

ELIZONDO, Salvador (2000a): Farabeuf o la crónica de un instante. Ed. Eduardo Becerra. Madrid, Ediciones Cátedra (Letras Hispánicas) [1965].

--- (2000b): El hipogeo secreto. 3. a ed. México, Fondo de Cultura Económica (Letras Mexicanas) [1968].

--- (2000c): "El retrato de Zoe”. En su libro El retrato de Zoe y otras mentiras. 3. a ed. México, Fondo de Cultura Económica (Letras Mexicanas): 11-22. [1969].

--- (2000d): “Teoría mínima del libro". En su libro Cuaderno de escritura. México, Fondo de Cultura Económica (Letras Mexicanas): 9-15. [1969].

--- (2006): "La primera página de Finnegans Wake. Traducción y notas de Salvador Elizondo". Casa del Tiempo 89 (2006): 53-56. Disponible también en: http://www.uam.mx/difusion/casadeltiempo/89_jun_2006/casa_del_tiempo_num89_5 3_56.pdf $[20 / 01 / 2020]$.

GRANIELA RODRÍGUEZ, Magda (1989): "La experiencia lectural como rasgo unificador y divergente en «la escritura»: José Emilio Pacheco y Salvador Elizondo". Texto Crítico 40-41 (1989): 13-20.

GUTIÉRREZ DE VELASCO ROMO, Luz Elena (1984): "La escritura de la amputación o la amputación de la escritura. Análisis de Farabeuf o la crónica de un instante y una selección de cuentos de Salvador Elizondo". Tesis Doctoral. México, El Colegio de México. 
GUTIÉRREZ PIÑA, Claudia L. (2016): Las variaciones de la escritura. Una lectura crítica de El grafógrafo y de la obra de Salvador Elizondo. México/Toluca, El Colegio de México/Universidad Autónoma del Estado de México.

PIGLIA, Ricardo: (1999): "Nuevas tesis sobre el cuento". En su libro Formas breves. Buenos Aires, Temas Grupo Editorial: 103-134.

--- (2000): “Tesis sobre el cuento". Guaraguao. Revista de Cultura Latinoamericana IV/11 (2000): 17-19.

--- (2006): "Secreto y narración. Tesis sobre la nouvelle". En Eduardo Becerra (ed.), El arquero inmóvil. Nuevas poéticas sobre el cuento. Madrid, Páginas de Espuma: 187205.

RÉVÉSZ, Enkratisz (2003): "El asedio del enigma y la subversión en la temprana cuentística de Salvador Elizondo”. Tesis doctoral. Budapest: Eötvös Loránd Tudományegyetem.

(C) Petra Báder

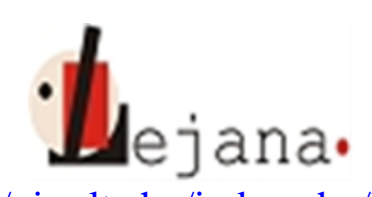

http://ojs.elte.hu/index.php/lejana

Universidad Eötvös Loránd, Departamento de Español, 1088 Budapest, Múzeum krt. 4/C 